\title{
Características fermentativas e bromatológicas de silagens de cana-de-açúcar com taboa
}

\author{
Fermentative and chemical characteristics of sugarcane silages with "taboa"
}

\author{
Mário Adriano Ávila Queiroz ${ }^{I^{*}}$ José Gledyson da Silva $^{\mathrm{I}}$ \\ Rosemary Lais GalatiI ${ }^{I I}$ Aparecida de Fátima Madella de Oliveira ${ }^{\text {III }}$
}

\section{RESUMO}

\begin{abstract}
Objetivou-se avaliar o potencial da taboa (Typha domingensis) como ingrediente, com diferentes níveis de inclusão em silagem de cana-de-açúcar (Saccharum officinalis), através de estudo dos parâmetros fermentativos. Utilizou-se delineamento experimental inteiramente casualizado com quatro tratamentos e seis repetições. Após 90 dias, com a abertura dos silos, determinaram-se os teores de carboidratos solúveis (CHO-Sol), etanol, ácidos orgânicos (lático, acético, propiônico, butírico), proteína bruta $(P B)$, matéria mineral $(M M)$, nutrientes digestíveis totais (NDT), digestibilidade in vitro a gás da matéria orgânica (DIVMO), pH e poder tampão (PT); estimou-se a perda total de MS, perdas por efluente e gases, densidade, e a recuperação da MS. Os níveis crescentes de taboa propiciaram diminuição $(P<0,05)$ da densidade nas silagens e aumento dos teores de PB, MM, NDT e DIVMO; muito embora não tenha se observado efeito $(P>0,05)$ sobre as perdas e recuperação da MS. As concentrações de etanol foram influenciadas $(P<0,05)$ pelo incremento de taboa, quando se observou redução de $76,92 \%$, com $40 \%$ de taboa em relação à silagem exclusiva de cana. A inclusão de taboa aumenta o conteúdo de proteína e minerais, bem como NDT e DIVMO, reduzindo significativamente a produção de etanol da silagem de cana-de-açúcar. A inclusão de taboa na ensilagem de cana-de-açúcar melhorou substancialmente as características fermentativas e o valor nutricional da massa ensilada.
\end{abstract}

Palavras-chave: Typha domingensis, Saccharum officinalis, ensilagem, fermentação alcoólica.

\section{ABSTRACT}

This study aimed to evaluate the potential of Typha domingensis ("taboa") as an ingredient with different inclusion levels in sugar cane (Saccharum officinalis) silage, by the study of the fermentative parameters. The experiment was carried out as a completely randomized design with four treatments and six replicates. After 90 days, of the silos'opening, the levels of water soluble carbohydrates, ethanol, organic acids (lactic, acetic, propionic, butyric acid), crude protein (CP), mineral matter (MM), total digestible nutrients (TDN), in vitro organic matter digestibility by gas (IVDOM), pH and buffer capacity; and, the losses by gas, effluent and total of dry mater, density and dry matter recovery were estimated. Increasing levels of "taboa" reduced $(P<0.05)$ silage density and increased the contents of CP, MM, TDN e IVDOM; although it has not been observed effect $(P>0.05)$ on the loss and recovery of DM. Ethanol concentrations were influenced $(P<0.05)$ by increment of "taboa" where reduction of $76.92 \%$ was observed, with $40 \%$ of "taboa" relative sugarcane silages exclusively. The inclusion of "taboa" increases the protein content and minerals, as well as TDN and IVDOM, also significantly reduces ethanol production of sugarcane silages. The inclusion of taboa in the ensiling of sugar cane substantially improved fermentation characteristics and nutritional value of the silage mass.

Key words: Typha domingensis, Saccharum officinalis, ensiling, alcoholic fermentation.

\section{INTRODUÇÃO}

No Brasil, tem-se observado valorização crescente do cultivo da cana-de-açúcar, sobretudo, na demanda de produção de biocombustíveis e uso na produção de forragem para alimentação animal (VOLTOLINI et al., 2012). Na alimentação de

IColegiado de Pós-graduação em Ciência Animal, Universidade Federal do Vale do São Francisco (UNIVASF), Rodovia BR 407, km 12,

lote 543, Projeto de Irrigação Nilo Coelho, S/N zona rural, 56310-770, Petrolina, PE, Brasil. E-mail: mario.queiroz@univasf.edu.br.

*Autor para correspondência.

ID Departamento de Zootecnia e Extensão Rural, Faculdade de Agronomia e Medicina Veterinária (FAMEV), Universidade Federal de Mato Grosso (UFMT), Cuiabá, MT, Brasil.

IIIInstituto Federal de Educação, Ciência e Tecnologia do Espírito Santo (IFES), Alegre, ES, Brasil. Recebido 04.02.14 Aprovado 29.05.14 Devolvido pelo autor 01.09.14 CR-2014-0164.R1 
ruminantes, a ensilagem da cana-de-açúcar pode tornarse determinante. Trata-se de uma tática frente à escassez de forragem em detrimento da estacionalidade, aliando, ainda, maior eficiência de emprego de tratos culturais necessários para a obtenção de alta produtividade $\mathrm{e}$ longevidade dos canaviais.

Apesar disso, a ensilagem de cana-de -açúcar exclusiva possui alguns entraves, como a considerável concentração de etanol, que é produzida no processo fermentativo, tendo em vista o alto teor de sacarose da cana, que facilmente é convertido a álcool. Isso modifica o padrão fermentativo da silagem, com significativa perda de MS, em torno de 49\% (SCHMIDT et al., 2007), além dos baixos teores de minerais e proteína $(\leq 3 \%)$ observados (PEDROSO et al., 2005).

Dessa forma, a taboa (Typha domingensis), planta macrófita aquática, típica de brejos, várzeas e outros espelhos de água, pode constituir alternativa em associação à cana no processo de conservação por ensilagem, considerando, valores de $16,1 \%$ de PB e elevados teores de minerais (potássio - 7,3\%, sódio - 1,8\%, Cálcio - 1,57\% e Ferro - 51 $\mathrm{mg} \mathrm{kg}^{-1}$ ) obtidos por KINUPP \& BARROS (2008). A viabilidade de colheita dessa planta se restringe a áreas encharcadas e com lâmina d'água pouco profunda. Sua propagação é facilitada, podendo até mesmo ser cultivada.

Segundo SILVA et al. (2014), maiores concentrações de minerais na massa ensilada, concorrem para uma alta pressão osmótica, o protoplasma das células dos microrganismos se desidrata, havendo contração da membrana plasmática (plasmólise). Em virtude disso, o desenvolvimento de microrganismos indesejáveis é inibido (REZENDE et al., 2011).

Objetivou-se com este trabalho avaliar o efeito da inclusão de taboa em diferentes proporções, sobre as características fermentativas e bromatológicas da silagem de cana-de-açúcar.

\section{MATERIAL E MÉTODOS}

Para confecção das silagens foram utilizadas as forrageiras: cana-de-açúcar, variedade industrial RB 85-5536, e a taboa - Typha domingensis; colhidas manualmente com idade aproximada de um ano (rebrota), trituradas separadamente em forrageira estacionária, com tamanho de partícula variando de 20 a 30mm. Logo depois de triturada, a taboa foi espalhada e deixada à sobra por um período de 18 horas, com a finalidade de aumentar seu teor de matéria seca que era de $19 \%$.

Foram utilizados silos adaptados, constituídos de baldes plásticos de $0,025 \mathrm{~m}^{3}$ com tampas herméticas, tendo válvulas do tipo Bunsen para escape dos gases e quantificação gravimétrica destes. Para permitir a medida quantitativa do efluente produzido, acomodou-se $2 \mathrm{~kg}$ de areia seca no fundo dos silos experimentais, protegida com tela fina de plástico e camada de tecido de algodão.

Oportunamente, foram coletadas amostras de cada forragem fresca para determinação de matéria seca (AOAC, 1995), obtendo-se valores de 26,1\% para cana-de-açúcar e $29,8 \%$ para a taboa emurchecida, respectivamente.

Em seguida, procedeu-se à mistura experimental, obedecendo às devidas proporções $(0$, 20, 30 e 40\% de taboa em substituição à cana-deaçúcar, com base na matéria natural) e acomodação/ compactação nos silos por pisoteio.

Logo após, os silos foram vedados e pesados para mensuração dos valores de densidade. Após o período de 90 dias, os silos foram novamente pesados, em seguida, abertos e a silagem amostrada. O conjunto vazio (silo, tampa, areia, tela e tecido de algodão) foi pesado para quantificação do efluente produzido e determinação da perda por gases e perda total de MS, de acordo com JOBIM et al. (2007):

A recuperação de MS foi obtida com base na diferença entre a massa seca inicialmente ensilada (neste caso $100 \%$ ) e a perda total ocorrida durante o processo de conservação, expressa em porcentagem.

A densidade das silagens foi determinada em função da massa volumétrica da forragem ensilada, ou seja, relação entre massa verde compactada e o volume do silo, dada em $\mathrm{kg} \mathrm{MV} \mathrm{m}^{-3}$.

$\mathrm{Na}$ ocasião da retirada das silagens, foram coletadas amostras, desprezando-se as extremidades $(10 \pm 2 \mathrm{~cm})$, para obtenção de Matéria seca, Matéria mineral e Proteína bruta (AOAC, 1990), NDT, conforme STUTH et al. (1999) (NDT=DIVMO*1,05) e digestibilidade in vitro a gás da matéria orgânica (MENKE \& STEINGASS, 1988); e extrato aquoso (KUNG JR. et al., 1984), para determinação do pH, poder tampão e os teores de carboidratos solúveis (DUBOIS et al., 1956); ácido lático (SCHMIDT et al., 2007) em espectrofotômetro JENWAY-6405 UV/VIS ${ }^{\circledR}$; ácidos acético, propiônico e butílico, em cromatógrafo líquido-gasoso CLG (Hewlett Packard ${ }^{\circledR}$ 5890, series II) (PALMQUIST \& CONRAD, 1971); e o teor de etanol em analisador bioquímico YSI 2700 Select $^{\circledR}$.

$\mathrm{O}$ delineamento experimental foi $\mathrm{o}$ inteiramente casualizado (DIC) com seis repetições e quatro níveis de inclusão de taboa. Os resultados foram analisados pelo programa Statistical Analysis System (SAS, 2003), sendo anteriormente verificada a normalidade dos resíduos pelo teste de SHAPIROWILK (PROC UNIVARIATE) e as variâncias 
comparadas por contrastes ortogonais, com nível de significância de 5\% pelo PROC GLM. Como os níveis não são equidistantes, utilizou-se o PROC IML para gerar os vetores de cada contraste (linear, quadrática e desvio da quadrática). Posteriormente às análises de contrastes, quando significativas, determinaram-se os parâmetros das equações de regressão pelo PROC REG.

\section{RESULTADOS E DISCUSSÃO}

Na tabela 1, pode-se observar que a inclusão da taboa à cana-de-açúcar no preparo das silagens promoveu variação $(\mathrm{P}<0,05)$ nos valores de MS e densidade, parâmetros que determinam a porosidade da silagem, influenciando o grau de deterioração na armazenagem e na descarga do silo. O teor de MS sofreu acréscimo de 13,42\% (1,13 vezes) em relação aos níveis 0 e $40 \%$ de taboa. Já para densidade, constatou-se efeito linear decrescente.

Acredita-se que os níveis crescentes de taboa, assim como do teor de MS, possivelmente tenha proporcionado dificuldades no processo de compactação, ocasionando redução gradativa nos valores de densidade das silagens.

Diferença na densidade de $10 \mathrm{~kg} \mathrm{MV}$ $\mathrm{m}^{-3}$ entre os níveis $0-40 \%$ de taboa foi verificada, correspondente a uma redução de 2,0\% (1,02 vezes). Entretanto, os valores observados se encontram acima do limite estabelecido por MULLIGAN et al. (2002), como sendo determinante de silagens mal compactadas ( $<300 \mathrm{~kg} \mathrm{MV} \mathrm{m}^{-3}$ ) e abaixo de $650 \mathrm{~kg}$ MV $\mathrm{m}^{-3}$, estabelecido por SENGER et al. (2005), como silagem bem compactada e, consequentemente, tidas como de boa preservação.

A perda total de MS e as perdas ocasionadas por produção de efluente e por liberação de gases não foram afetadas $(\mathrm{P}>0,05)$ pela adição da taboa, como também a recuperação da MS das silagens, observando-se as médias 22,63\%, 41,10kg t $\mathrm{kV}^{-1} \mathrm{MV}$, $19,28 \%$ MS e $77,38 \%$, respectivamente (Tabela 1).

Foi observado, na abertura dos silos, que os tratamentos com maior inclusão de taboa apresentaram biomassa mais agregada, mais viscosa, como que se a taboa tivesse maior poder hidrofílico, que pode estar associado à pectina. É provável que esse comportamento esteja associado à maior retenção de água ao longo do perfil da silagem, minimizando as perdas por efluente. Segundo VAN SOEST (1994), a pectina possui alta capacidade de retenção de água (aumento da viscosidade), alta capacidade de troca catiônica e elevada adsorção de sais biliares, quando comparada a outros materiais fibrosos, fatores que podem influenciar significativamente a qualidade dos alimentos. O poder tampão que determina a velocidade de redução do $\mathrm{pH}$ foi influenciado $(\mathrm{P}<0,05)$ pelo incremento crescente da taboa (Tabela 2), ocorrendo acréscimo linear, obtendo-se aumento de 48,12\% (1,5 vezes), relacionando-se às inclusões $0-40 \%$ da taboa. Contudo, tal efeito não influenciou o $\mathrm{pH}(\mathrm{P}>0,05)$ nas silagens, frente aos níveis de taboa testados, observando-se média de 3,68.

A concentração de etanol nas silagens em estudo foram afetadas $(\mathrm{P}<0,05)$, com os níveis crescentes da taboa sobre a cana no preparo das silagens. Ocorreu diminuição de 76,92\% (4,3 vezes) da produção de álcool, ponderando-se os intervalos 0 e $40 \%$ de incremento. No entanto, não se observou variação nos teores de carboidratos solúveis, apresentando média de 3,53\% da MS.

Esperava-se uma resposta diferente dos carboidratos solúveis em virtude dos valores significativos do etanol, uma vez que WOOLFORD (1984) reporta que a natureza química deste açúcar parece favorecer o desenvolvimento de leveduras durante a ensilagem, que convertem a sacarose em etanol. Corroborando PEDROSO (2003), que

Tabela 1 - Teor de matéria seca, perdas fermentativas, recuperação de matéria seca e densidade de silagens de cana-de-açúcar em associação com taboa.

\begin{tabular}{|c|c|c|c|c|c|c|c|}
\hline \multirow{2}{*}{ Variáveis } & \multicolumn{4}{|c|}{---------Níveis de taboa (\%)--------- } & \multirow{2}{*}{$\mathrm{EPM}^{(1)}$} & \multirow{2}{*}{$\mathrm{R}^{2}$} & \multirow{2}{*}{$\mathrm{ER}^{(2)}$} \\
\hline & 0 & 20 & 30 & 40 & & & \\
\hline Matéria seca, \% & 23,1 & 24,2 & 25,6 & 26,2 & 0,317 & 0,85 & $y=22,97+0,08 x^{*}$ \\
\hline Perdas por efluente, $\mathrm{kg} \mathrm{t}^{-1} \mathrm{MV}$ & 39,1 & 40,1 & 42,7 & 42,5 & 0,830 & - & $y=41,10$ \\
\hline Perdas por gases, $\% \mathrm{MS}$ & 20,4 & 19,2 & 19,1 & 18,4 & 0,344 & - & $y=19,28$ \\
\hline Perda total de matéria seca, $\%$ & 23,5 & 22,5 & 22,6 & 21,9 & 0,316 & - & $y=22,63$ \\
\hline Recuperação da matéria seca, \% & 76,5 & 77,5 & 77,4 & 78,1 & 0,316 & - & $y=77,38$ \\
\hline Densidade, $\mathrm{kg} \mathrm{MV} \mathrm{m}^{-3}$ & 511,3 & 499,3 & 499,3 & 501,3 & 1,744 & 0,45 & $y=507,3-0,15 x^{*}$ \\
\hline
\end{tabular}

*Significativo $\mathrm{P}<0,05 .{ }^{(1)}$ Erro-padrão da média. ${ }^{(2)}$ Equação de regressão, teste de polinômio ortogonal, resposta linear, quadrática ou cúbica.

Ciência Rural, v.45, n.1, jan, 2015. 
Tabela 2 - Valores de pH, poder tampão (PT), carboidratos solúveis (CHO-Sol), Etanol, proteína bruta (PB), matéria mineral (MM), Digestibilidade in vitro da matéria orgânica (DIVMO), Nutrientes Digestíveis Totais (NDT) e ácidos orgânicos (acetato, propionato, butirato e lactato) de silagens de cana-de-açúcar com diferentes proporções de taboa.

\begin{tabular}{|c|c|c|c|c|c|c|c|}
\hline \multirow{2}{*}{ Variáveis } & \multicolumn{4}{|c|}{--------Níveis de taboa $(\%)-$} & \multirow{2}{*}{$\mathrm{EPM}^{(1)}$} & \multirow{2}{*}{$\mathrm{R}^{2}$} & \multirow{2}{*}{$\mathrm{ER}^{(2)}$} \\
\hline & 0 & 20 & 30 & 40 & & & \\
\hline $\mathrm{pH}$ & 3,60 & 3,70 & 3,70 & 3,70 & 0,019 & - & $y=3,68$ \\
\hline Poder tampão ${ }^{(3)}$ & 23,90 & 33,70 & 31,60 & 35,40 & 1,116 & 0,68 & $y=26,29+0,162 x^{*}$ \\
\hline Carboidratos solúveis ${ }^{(4)}$ & 4,10 & 3,60 & 3,10 & 3,30 & 0,173 & - & $y=3,53$ \\
\hline Etanol $^{(4)}$ & 23,40 & 13,70 & 8,10 & 5,40 & 1,514 & 0,90 & $y=23,04-0,46 x^{*}$ \\
\hline Proteína bruta ${ }^{(4)}$ & 3,22 & 4,87 & 5,91 & 6,91 & 0,288 & 0,98 & $\mathrm{y}=3,15276+0,09225 \mathrm{x}^{*}$ \\
\hline Matéria mineral ${ }^{(4)}$ & 2,88 & 4,32 & 5,22 & 5,97 & 0,244 & 0,97 & $\mathrm{y}=2,84610+0,07791 \mathrm{x}^{*}$ \\
\hline $\mathrm{NDT}^{(5)(6)}$ & 69,43 & 70,01 & 70,34 & 71,82 & 0,588 & 0,82 & $y=69,18755+0,05392 x^{*}$ \\
\hline $\operatorname{DIVMO}^{(5)(7)}$ & 66,13 & 66,67 & 67,00 & 68,40 & 0,213 & 0,90 & $y=65,977+0,0357 x^{*}$ \\
\hline Ácido acético ${ }^{(4)}$ & 2,40 & 2,90 & 6,30 & 4,00 & 0,494 & 0,59 & $y=1,97+0,146 x-0,0018 x^{2} *$ \\
\hline Ácido propiônico ${ }^{(4)}$ & 0,076 & 0,078 & 0,094 & 0,088 & 0,002 & 0,62 & $y=0,0762+0,0003 x^{*}$ \\
\hline Ácido butírico ${ }^{(4)}$ & 0,008 & 0,008 & 0,007 & 0,004 & 0,001 & - & $y=0,007$ \\
\hline Ácido láctico ${ }^{(4)}$ & 2,60 & 1,80 & 0,90 & 0,80 & 0,223 & 0,92 & $y=2,4512-0,0317 x^{*}$ \\
\hline
\end{tabular}

Significativo $\mathrm{P}<0,05 .{ }^{(1)}$ Erro-padrão da média. ${ }^{(2)}$ Equação de regressão, teste de polinômio ortogonal, resposta linear, quadrática ou cúbica. ${ }^{(3)}$ Meq de $\mathrm{HCl} 100 \mathrm{~g}^{-1}$ MS. ${ }^{(4)} \%$ da MS. ${ }^{(5)} \%$ da MO. ${ }^{(6)}$ Nutrientes Digestíveis Totais (NDT = DIVMO*1,05), STUTH et al. (1999). ${ }^{(7)}$ Digestibilidade in vitro da Matéria Orgânica.

observou concentrações de etanol inversamente correlacionadas com o teor de carboidratos solúveis residuais $(\mathrm{r}=-0,863)$, confirmando que a produção de etanol consome açúcares da silagem, causando diminuição do seu valor nutritivo.

Os ácidos orgânicos (Tabela 2), com exceção do ácido butírico, foram influenciados $(\mathrm{P}<0,05)$ pelo incremento crescente de taboa sobre a cana-de-açúcar. O ácido acético apresentou comportamento quadrático, função crescente nos níveis 0 a $30 \%$ de taboa, e decrescente em seguida. Com valor mínimo de $2,4 \%$ e máximo de 6,3\% da MS; 1,2 e 3,2 vezes (para máximo e mínimo, respectivamente) superior ao proposto por ROTH \& UNDERSANDER (1995) como aceitável (>2,0\% da MS); podendo, assim, possivelmente, comprometer o consumo animal.

No entanto, considerável concentração deste ácido mostrou-se eficaz em reduzir a população de leveduras (TAYLOR et al., 2002) e consequentemente a concentração de etanol, podendo justificar desta forma os resultados observados para a variável etanol neste trabalho, tendo em vista que o ácido acético possui princípio antifúngico sobre a fermentação (KLEINSCHMIT et al., 2005).

Considerando a linha de tendência projetada pela equação proposta $(\hat{y}=1,97+0,146 x-$ $\left.0,0018 x^{2}, R=0,59\right)$, têm-se maior produção deste ácido (4,9\% da MS) com respectiva adição de 40,6\% de taboa em substituição do ingrediente cana-deaçúcar no momento da preparação das silagens.

O ácido propiônico sofreu incremento com a adição da taboa, verificando-se aumento de 15,8\%, considerando-se os níveis 0 e $40 \%$; muito embora os níveis observados nas silagens não representem perigo à qualidade da silagem com a degradação do ácido lático, uma vez que, tais concentrações encontramse dentro de faixa estabelecida $(<0,50 \%$ da MS) por ROTH \& UNDERSANDER (1995) (Tabela 2). Por outro lado, o propionato, assim como o ácido acético, possui princípios antifúngicos (KUNG JR et al., 2003) e desempenha importante papel no controle de leveduras em silagens e possivelmente tenha também contribuído para a menor produção de etanol verificada neste estudo.

O ácido butírico, que reflete a influência da atividade clostridiana sobre material ensilado, tida como um dos principais indicadores negativos da qualidade do processo fermentativo, não foi significativo $(\mathrm{P}>0,05)$ aos níveis testados, apresentando média de $0,007 \%$ da MS, classificada por VIEIRA et al. (2004) como "muito boa" ( $<0,1 \%$ da MS).

A concentração de ácido lático nas silagens estudadas sofreu redução $(\mathrm{P}<0,05)$ de 69,2\% com a adição da taboa (Tabela 2), considerando-se os níveis 
0-40\%. O maior valor observado para esta variável foi 2,6\% da MS, na silagem exclusiva de cana-de-açúcar ( $0 \%$ de taboa); classificada, segundo VIEIRA et al. (2004), como silagem "satisfatória" (3,0-2,0\% da MS).

Acredita-se que, possivelmente, deva ter ocorrido dominância de bactérias heterofermentativas, por existir condições favoráveis a estas (aeração crescente em resposta à menor densidade, por formação de poros na massa ensilada), inibindo a atuação das bactérias láticas homofermentativas, que, de acordo com McDONALD et al. (1991), são predominantes no início do processo fermentativo e, quando bem instaladas, logo favorecem a inibição de outras bactérias de fermentação secundária, dado pela mais rápida diminuição do $\mathrm{pH}$.

O teor de matéria mineral foi influenciado $(\mathrm{P}<0,05)$ pela adição da taboa nas silagens de cana, observando-se resposta linear crescente $\left(\hat{y}=2,85+0,08 x, r^{2}=0,97\right)$, verificando-se aumento na ordem de $107 \%$, considerando-se os níveis 0 e $60 \%$ de taboa. SILVA et al. (2014), em estudo de associação da erva sal na ensilagem de cana-de-açúcar, também observaram efeito linear crescente no teor de material mineral dessas silagens, melhorando tanto sua composição química quanto as características fermentativas.

$\mathrm{O}$ incremento de taboa proporcionou $(\mathrm{P}<0,05)$ acréscimo no teor de $\mathrm{PB}$ nas silagens de cana-de-açúcar, quando se constatou efeito linear crescente, obtendo-se aumentos de 115,6\%, observando-se os tratamentos 0 e $60 \%$ de taboa.

A digestibilidade in vitro da matéria orgânica das silagens estudas foram afetadas $(\mathrm{P}<0,05)$ pela inclusão de taboa, tendo-se comportamento linear crescente, ajustado à equação de regressão, observando-se acréscimo de 3,43\% (1,03 vezes), quando se consideram os níveis 0 e $60 \%$ de taboa em substituição à cana no preparo da silagem.

Mesmo com o incremento de MM, não se observou prejuízo nos níveis de energia, no que diz respeito à concentração de NDT, verificando-se acréscimo de 2,39 vezes, relacionando-se os níveis mínimo e máximo testados neste experimento (Tabela 2).

\section{CONCLUSÃO}

A inclusão de taboa na ensilagem de canade-açúcar proporcionou efeito associativo positivo ao melhorar substancialmente as características fermentativas e o valor nutricional da massa ensilada. Contudo, deve-se levar em consideração o manejo sustentável e legal do corte da taboa.

\section{REFERÊNCIAS}

AOAC (ASSOCIATION OF OFFICIAL ANALYTICAL CHEMISTS). Official Methods of Analysis. Washington: Association of Official Analytical Chemists, 1995. p. 1141.

DUBOIS, M. et al. Colorimetric method for determination of sugars and related substances. Analytical Chemistry, v.28, p.350, 1956.

JOBIM, C.C. et al. Avanços metodológicos na avaliação da qualidade da forragem conservada. Revista Brasileira de Zootecnia, v.36, 2007. p.101-119. Disponível em: <http://www. scielo.br/pdf/rbz/v36s0/13.pdf.>. Acesso em: 22 dez. 2012. doi: 10.1590/S1516-35982007001000013.

KINUPP, V.F.; BARROS, I.B.I. Teores de proteína e minerais de espécies nativas, potenciais hortaliças e frutas. Ciência e Tecnologia de Alimentos, v.28, n.4, p. 846-857, 2008. Disponível em: 〈http://www.scielo.br/pdf/cta/v28n4/a13v28n4.pdf〉. Acesso em: 10 jan. 2014. doi: 10.1590/S0101-20612008000400013.

KLEINSCHMIT, D.H. et al. The effects of various antifungal additives on the fermentation and aerobic stability of corn silage. Journal of Dairy Science, v.88, p.2130-2139, 2005. Disponível em: <http://www.sciencedirect.com/science/article/pii/ S0022030205728897>. Acesso em: 22 dez. 2012. doi: 10.3168/ jds.S0022-0302(05)72889-7.

KUNG JR., L. et al. Added ammonia or microbial inocula for fermentation and nitrogenous compounds of alfalfa ensiled at various percents of dry matter. Journal of Dairy Science, v.67, p.299-306, 1984. Disponível em: <http://www.sciencedirect.com/ science/article/pii/S0022030284813028>. Acesso em: $21 \mathrm{dez}$. 2012. doi: 10.3168/jds.S0022-0302(84)81302-8.

KUNG JR, L. et al. Silage additives. In: BUXTON, D.R et al. (Ed.). Silage science and technology. Wisconsin: ASA, 2003. p.305-360.

McDONALD, P. et al. The biochemistry of silage. 2.ed. Marlow: Chalcombe, 1991. 340p.

MENKE, K.H.; STEINGASS, H. Estimation of the energetic feed value obtained from chemical analysis and gas production using rumen fluid. Animal Research Development, v.28, p.7-55, 1988.

MULLIGAN, F.J. et al. Intake, digestibility, milk production and kinetics of digestion and passage for diets based on maize or grass silage fed to late lactation dairy cows. Livestock Production Sciences, v.74, p.113-124, 2002. Disponível em: <http://www. sciencedirect.com/science/article/pii/S0301622601002986>. Acesso em: 10 jan. 2014. doi: 10.1016/S0301-6226(01)00298-6.

PALMQUIST, D.; CONRAD, H. Origin of plasma fatty acids in lactating cows fed high fat diets. Journal of Dairy Science, v.54, p.1025-1033, 1971. Disponível em: <http://www.sciencedirect. com/science/article/pii/S0022030271859660>. Acesso em: $21 \mathrm{dez}$. 2012. doi: 10.3168/jds.S0022-0302(71)85966-0.

PEDROSO, A.F. Aditivos químicos e microbiano no controle de perdas e na qualidade de silagem de cana-de-açúcar (Sccharum officinarum L.). 2003. 120f. Tese (Doutorado em Agronomia) - Curso de Pós-graduação em Zootecnia, Escola Superior de Agricultura Luiz de Queiroz, Piracicaba, SP 
PEDROSO, A.F. et al. Fermentation and epiphytic microflora dynamics in sugar cane silage. Scientia Agricola, v.62, n.5, p.427-432, 2005. Disponível em: <ttp://www.scielo.br/pdf/sa/ v62n5/25980.pdf>. Acesso em: 21 dez. 2012. doi: 10.1590/ S0103-9016.2005.000500003.

REZENDE, A.V. et al. Perdas fermentativas e estabilidade aeróbia de silagens de cana-de-açúcar tratadas com cal virgem e cloreto de sódio. Revista Brasileira de Zootecnia, v.40, n.4, p.739-746, 2011. Disponível em: <http://www.scielo.br/pdf/rbz/ v40n4/06.pdf >. Acesso em: 26 jul. 2013. doi: 10.1590/S151635982011000400006.

ROTH, G.; UNDERSANDER, D. Silage additives. In: Corn silage production management and feeding. Madison: American Society of Agronomy, 1995. p.27-29.

SAS INSTITUTE. SAS/STAT: guide for personal computer; version 9.1. Cary, 2003. 235p.

SCHMIDT, P. et al. Aditivos químicos e biológicos na ensilagem de cana-de-açúcar. 1. Composição química das silagens, ingestão, digestibilidade e comportamento ingestivo. Revista Brasileira de Zootecnia, v.36, p.1666-1675, 2007. Disponível em: <http://www. scielo.br/pdf/rbz/v36n5s0/a27v3650.pdf>. Acesso em: $21 \mathrm{dez}$. 2012. doi: 10.1590/S1516-3598.2007.000700027.

SENGER, C.C.D. et al. Composição química e digestibilidade "in vitro" de silagens de milho com distintos teores de umidade e níveis de compactação. Ciência Rural, v.35, n.6, p.1393-1399, 2005. Disponível em: <http://www.lume.ufrgs.br/bitstream/ handle/10183/22188/000520143.pdf?sequence $=1>$. Acesso em: 10 jan. 2014. doi: 10.1590/S0103-84782005000600026.

SILVA,J.G. et al. Características fermentativas de silagens de canade-açúcar com erva sal. Ciência Rural, v.44, n.3, p.555-560, 2014
Disponível em: <http: http://www.scielo.br/scielo.php?script=sci_ issuetoc $\&$ pid $=010347820140003 \& \operatorname{lng}=p t \& n r m=i s o>$. Acesso em: 02 maio 2014. doi: 10.1590/S0103-84782014000300027.

STUTH, J.W. et al. Nutritional management of free-grazing livestock. In: JUNG, H.G.; FAHEY, G.C. Nutritional ecology of herbivores. Proceedings of the International Symposium on the Nutrition of Herbivores, 5. Savoy: American Society of Animal Science, 1999. p.696-731.

TAYLOR, C.C. et al. The effect of treating whole-plant barley with Lactobacillus buchneri 40788 on silage fermentation, aerobic stability and nutritive value for dairy cows. Journal of Dairy Science, v.85, n.7, p.1793-1800, 2002. Disponível em:<http:// www.researchgate.net/publication/11186111>. Acesso em: $21 \mathrm{dez}$. 2012. doi: 10.3168/jds.S0022-0302(02)74253-7.

VAN SOEST, P.J. Nutritional ecology of the ruminant. 2.ed. New York: Cornell University, 1994. 476p.

VIEIRA, F.A.P. et al. Qualidade de silagens de sorgo com aditivos. Arquivos Brasileiros de Medicina Veterinária e Zootecnia, v.56, n.6, p.764-772, 2004. Disponível em: <http://www.scielo.br/ pdf/abmvz/v56n6/a11v56n6.pdf $>$. Acesso em: 10 jan. 2014. doi: 10.1590/S0102-09352004000600011.

VOLTOLINI, T.V. et al. Valor nutritivo de cultivares de cana-deaçúcar sob irrigação. Revista Brasileira de Saúde e Produção Animal, v.13, p.894-901, 2012. Disponível em: <http://revistas. ufba.br/index.php/rbspa/article/view/2366/1312>. Acesso em: 10 jan. 2014. doi: 10.1590/S1519-99402012000400001.

WOOLFORD, M.K. The silage fermentation. New York: Marcel Dekker, 1984. p.23-132. 